\title{
Chromosome 22q11 microdeletions in tetralogy of Fallot
}

\author{
A H Trainer, N Morrison, A Dunlop, N Wilson, J Tolmie
}

\begin{abstract}
Chromosome 22q11 fluorescence in situ hybridisation (FISH) studies were performed on 33 consecutive individuals attending a paediatric cardiology clinic with tetralogy of Fallot. Seven children had 22q11 microdeletions but only four had other clinical features associated with the newly recognised chromosome 22 deletion syndrome (CATCH 22). Chromosome 22q11 FISH studies should therefore be performed on all patients with tetralogy of Fallot.

(Arch Dis Child 1996; 74: 62-63)
\end{abstract}

Keywords: tetralogy of Fallot, 22q11 microdeletions, CATCH 22

Tetralogy of Fallot is the commonest cyanotic congenital cardiac defect and may occur either as an isolated abnormality or in association with other non-cardiac malformations. ${ }^{1}$ Recognisable syndromes associated with tetralogy of Fallot include DiGeorge syndrome and velocardiofacial syndrome both of which may arise from microdeletion of chromosome 22q11.2 This very small chromosome aberration is best identified by specialised molecular cytogenetic studies employing the fluorescence in situ hybridisation (FISH) technique. Chromosome 22q11 microdeletions have recently been documented in patients with tetralogy of Fallot alone, ${ }^{3}$ and it is not clear what percentage of all patients with this condition have an underlying submicroscopic or cryptic chromosome 22 abnormality. In individual cases this information will alter the risk of recurrence after one affected child which is normally derived from empiric data. ${ }^{4}$ We therefore performed 22q11 FISH studies on 33 sequential patients attending a paediatric cardiology clinic with a diagnosis of tetralogy of Fallot in order to investigate the prevalence of $22 \mathrm{q} 11$ deletions in this population and identify families with familial and sporadic 22q11 microdeletions. \section{Sick Children,}

Royal Hospital For Glasgow, Duncan Guthrie Institute of Medical Genetics

A $\mathrm{H}$ Trainer

N Morrison

A Dunlop

J Tolmie

\section{Department of}

Cardiology

$\mathrm{N}$ Wilson

Correspondence to: Dr A H Trainer, Duncan Guthrie Institute of Medical Genetics, Yorkhill Hospital Genetics, Yorkhill Hosp NHS Trust, Glasgow

G3 8SJ.

Accepted 5 September 1995

\section{Subjects and methods}

We approached 40 consecutive families attending the cardiology clinic with a child with tetralogy of Fallot. A three generation family tree was drawn and the child evaluated for clinical features suggestive of an underlying syndrome diagnosis. Blood was taken for routine chromosome banding studies and specialised FISH studies using cosmids sc11.1, E0472, sc4.1, and D0832 all of which map to 22q11. In children with a chromosome abnormality, its origin was investigated through examination of parental blood samples.

\section{Results}

Seven families from the 40 who were approached refused a blood sample. The remaining 18 males and 15 females included two children with trisomy 21 Down's syndrome.

Routine chromosome preparations were normal in 30 patients and one was noted to have a coincidental familial chromosome 13 paracentric inversion.

Seven patients had microdeletions at $22 \mathrm{q} 11$ detected by FISH. Three of these patients were clinically diagnosed as having velocardiofacial syndrome, one in the course of this study and two while attending the cleft palate clinic. In two of these families one parent was not available and both parents in the third family, neither of whom had clinical features, refused to give blood samples, although they had two daughters with velocardiofacial syndrome and 22q11 microdeletion.

The fourth patient with a chromosome $22 \mathrm{q} 11$ microdeletion, which was not present in either parent, had a previous clinical diagnosis

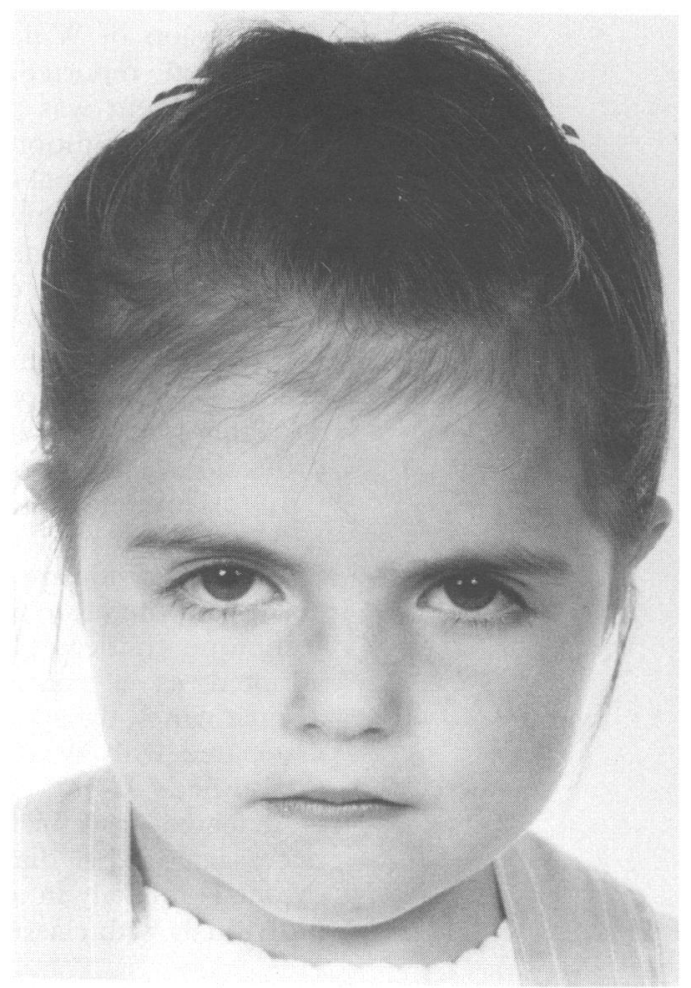

Girl with isolated tetralogy of Fallot associated with a chromosome 22q11 microdeletion. 
of partial DiGeorge syndrome. The remaining three patients with chromosome 22 microdeletions had isolated tetralogy of Fallot with no other clinical features to suggest this underlying chromosome abnormality. In these three, the chromosome deletions were not familial.

\section{Discussion}

In this study we identified three patients (11\%) who have tetralogy of Fallot as the only clinical feature of an underlying chromosome 22q11 microdeletion. Recently, this chromosome abnormality has been associated with diverse abnormalities signified by the acronym CATCH 22 (cardiac defects, abnormal facies, thymic aplasia/hypoplasia, cleft palate, hypoparathyroidism, and microdeletion of 22q11). While another study of $22 \mathrm{q} 11$ deletions in tetralogy of Fallot ${ }^{6}$ confirmed the presence of deletions in the majority of cases associated with velocardiofacial syndrome and DiGeorge syndrome, no deletions were identified in otherwise non-dysmorphic individuals. In fact, the authors of this study admitted that, in some of their cases, suggestive dysmorphic features were only identified after the chromosome abnormality was detected. In our experience, some patients with chromosome 22q11 microdeletion have either no dysmorphic features or very subtle features which are easily overlooked (figure)

In an epidemiological study of tetralogy of Fallot, ${ }^{1}$ non-cardiac malformations were found in only $27 \%$ of patients, made up of $8 \%$ with a clinically recognisable syndrome, $8 \%$ with chromosome aneuploidy, and $11 \%$ with no underlying diagnosis. Therefore, the important implication of our small study is that FISH analysis should be routinely performed in patients where tetralogy of Fallot occurs as an isolated malformation. Identification of this chromosome deletion highlights the possibility of other associated problems, such as immunological disorders or learning disabilities, also known to be associated with $22 \mathrm{q} 11$ microdeletion. From the parents' perspective, identifying the chromosome deletion clarifies the sibling recurrence risk and facilitates genetic counselling for the affected child who may ask for advice in the future.

We are indebted to Professor P J Scambler for the probes sc11.1, sc4.1, E0472, and D0832 that were used in this study. We also wish to thank Dr W Doig and Dr A Houston, consultant paediatric cardiologists, for their advice and help in this study.

1 Karr SS, Brenner JL, Loffredo C, Neill CA, Rubin JD Tetralogy of Fallot. The spectrum of severity in a regional study. Am $\mathcal{F}$ Dis Child 1992; 146: 121-4.

2 Driscoll DA, Salvin J, Sellinger B, et al. Prevalence of 22q11 microdeletions in DiGeorge and velo-cardio-facial syndromes: implications for genetic counselling and prenatal diagnosis. $\mathcal{F}$ Med Genet 1993; 30: 813-7.

3 Goldmuntz E, Driscoll D, Budarf ML, et al. Microdeletions of chromosomal region $22 \mathrm{q} 11$ in patients with congenita conotruncal cardiac defects. 7 Med Genet 1993; 30 807-12.

4 Boon AR, Farmer MB, Roberts DF. A family study of Fallot's tetralogy. $\mathcal{F}$ Med Genet 1972; 9: 179-92.

5 Wilson DI, Burn J, Scambler P, Goodship J. Syndrome of the month. DiGeorge syndrome, part of CATCH 22. $f$ Med Genet 1993; 30: 852-6.

6 Amati A, Mari A, Digilio MC, et al. 22q11 deletions in isolated and syndromic patients with tetralogy of Fallot. Hum lated and syndromic patient $1995 ; 95: 479-82$. 